\title{
ARITMÉTICA AMBIENTAL APLICADA À ANÁLISE DOS IMPACTOS DAS PLANTAÇÕES DE BIOCOMBUSTÍVEIS E FLORESTAS
}

\author{
ARITMÉTICA AMBIENTAL APLICADA AL ANÁLISIS DE LOS \\ IMPACTOS DE LAS PLANTACIONES DE BIOCOMBUSTIBLES Y \\ FLORESTAS
}

\section{ENVIRONMENTAL ARITHMETIC APPLIED TO THE IMPACTS ANALYSIS OF THE BIOFUELS AND FOREST PLANTATIONS}

\author{
Birgit Yara Frey Riffel \\ Centro Federal de Educação Tecnológica de Minas Gerais \\ birgit@araxa.cefetmg.br \\ Beatriz Aparecida Bessa Florêncio \\ Instituto de Geografia - Universidade Federal de Uberlândia \\ beatrizflorencio@gmail.com \\ Tatiana Diniz Prudente \\ Instituto de Geografia - Universidade Federal de Uberlândia \\ tatyprudente@yahoo.com.br \\ Alexandre Luiz Alves \\ Instituto de Geografia - Universidade Federal de Uberlândia \\ alexandreluizalves@yahoo.com.br
}

\section{RESUMO}

$\mathrm{O}$ aquecimento global tem preocupado grande parte das nações do mundo, e sido tema de conferências que discutem quais ações devem ser executadas pelos países e governos locais para permitir que o desenvolvimento seja sustentável, e não acarrete prejuízos ambientais, sociais, culturais ou econômicos. É um equacionamento difícil, que implica em mudanças nas matrizes energéticas, nos hábitos de consumo, nas atividades industriais, nos paradigmas de preservação ambiental, enfim, em toda a sociedade. $\mathrm{O}$ presente trabalho analisa os impactos que a implantação de reflorestamentos destinados a seqüestrar carbono emitido por queima de combustíveis fósseis e a plantação de biocombustíveis têm sobre a produção de alimentos, sobre a ocupação do solo e sobre o estoque de gases estufa no mundo. Propõe ainda um modelo para enfrentar estes impactos, respondendo às diretrizes das conferências de Quioto (1997) e de Bali (2007). 
Palavras-chave: Aquecimento global; reflorestamentos; biocombustíveis; impactos ambientais; sustentabilidade.

\title{
RESUMEN
}

El calentamiento global ha preocupado a gran parte de las naciones del mundo, $\mathrm{y}$ ha sido tema de conferencias que discuten cuales son las acciones que deben ser ejecutadas por los países y gobiernos locales para permitir que el desarrollo sea sustentable, y no acarree perjuicios ambientales, sociales, culturales o económicos. Es una cuestión difícil, que significa que debe haber cambios en las matrices energéticas, en los hábitos de consumo, en las actividades industriales, en los paradigmas de preservación ambiental, en fin, en toda la sociedad. El presente trabajo analiza los impactos que la implantación de reforestación destinada a secuestrar carbono emitido por la quema de combustibles fósiles y la plantación de biocumbustibles tienen sobre la producción de alimentos, sobre la ocupación del suelo y sobre el stock de gases estufa en el mundo. Propone también un modelo para enfrentar estos impactos, respondiendo a las directrices de las conferencias de Kyoto (1997) y de Bali (2007).

Palabras-clave: Calentamiento global; reforestación; biocombustibles; impactos ambientales; sustentabilidad.

\begin{abstract}
Global warming has been a worry to many countries around the world. And it has been the subject of conferences that have discussed which actions should be taken by countries and local governments to allow sustainable development and not cause environmental, social, cultural or economical losses. It is a tough equation that means changes in: energetic sources, consumption habits, industrial activities, environmental preservation paradigms, after all, the whole society. The current assignment analyses the impacts that the implementation of reforestation meant to seize carbon emitted by the burning of fossil fuel and the plantation of biofuel have on food production, land occupation and on greenhouse gases reserves in the world. It also proposes a model to face these impacts, in response to the Kyoto's (1997) and Bali's (2007) protocol.
\end{abstract}

Key-words: Global warming, reforestation, biofuels, environmental impacts, sustainability 


\section{Introdução}

A forma como a humanidade vem suprindo ao longo da história a demanda crescente por energia e os impactos disso sobre o meio ambiente, são assuntos tratados especialmente nas últimas três décadas, sob a ótica do "desenvolvimento sustentável".

Atualmente um dos maiores desafios das sociedades é o de construir e manter comunidades sustentáveis. A matriz energética predominantemente utilizada no mundo causa uma série de problemas que afetam não só as variáveis climáticas, como também as sociais e econômicas. Os modelos globais de mudanças climáticas já dão como certo o aumento da freqüência de enchentes, secas e tempestades, que se tornarão a cada dia mais intensas, destruindo plantações, vidas e prejudicando a economia.

\section{Metodologia}

Como forma de analisar os impactos dos reflorestamentos e das plantações de biocombustíveis sobre a ocupação do solo, sobre a produção de alimentos e sobre o estoque de gases de efeito estufa (GEE) no mundo elaborou-se um modelo que responda às diretrizes da $3^{\text {a }}$ Conferência das Partes das Nações Unidas, realizada em Quioto, no ano de 1997 e da $13^{\text {a }}$ Conferência Quadro das Nações Unidas, realizada em Bali no ano de 2007.

Para tal foram feitos cálculos de aritmética ambiental e estimadas metas físicas e temporais referentes ao município ideal de Toribaté, com projeções de crescimento até o ano de 2050 - prazo final estipulado para o cumprimento de algumas das metas previstas no documento de Bali para os países não desenvolvidos.

Município brasileiro de médio porte, Toribaté tem sido utilizado como modelo em diversas análises ambientais. Permite, através de uma avaliação pragmática, que questões ambientais, diretrizes e propostas de ações sejam extrapoladas para outros municípios existentes. É caracterizado como tendo em 2008 população de 583.810 habitantes, e área de $1300 \mathrm{~km}^{2}$, dos quais $300 \mathrm{~km}^{2}$ são de área urbana (FEHR, 2008). 


\section{As Alterações Climáticas Globais e as Conferências Mundiais para o Desenvolvimento Sustentável}

A poluição do ar, causada principalmente pela industrialização, é a principal responsável pelo efeito estufa e está por detrás de inúmeros problemas ambientais. A crescente preocupação com o aumento das taxas de emissão de gases de efeito estufa e suas implicações sobre o clima levaram à diversas negociações internacionais, que culminaram com conferências sobre Mudanças Climáticas das Nações Unidas (IPCC, 2007), com os Tratados de Quioto e de Bali.

O Protocolo de Quioto foi o documento resultante da $3^{\text {a }}$ Conferência das Partes da Convenção das Nações Unidas sobre Mudanças Climáticas, realizada no Japão, em 1997. Nesse protocolo foram estabelecidas reduções nas emissões de dióxido de carbono $\left(\mathrm{CO}_{2}\right)$ e outros gases do efeito estufa, nos países industrializados, chamados de Anexo 1. Esse grupo de países deveria reduzir a emissão de poluentes em 5,2\% em relação aos níveis de 1990, em cotas diferenciadas de até 8\%, entre 2008 e 2012.

Os signatários do protocolo deveriam garantir até o ano de 2005, um progresso significativo na redução de suas emissões. O protocolo entrou em vigor 90 dias após a data em que pelo menos 55 signatários, que contabilizam no total $55 \%$ das emissões totais de dióxido de carbono em 1990, tinham depositado seus instrumentos de ratificação, aceitação ou adesão. Mas, segundo a ONU, a estabilização do clima exigiria reduções bem maiores, entre 60 e 80\% (GARDNER, 2002).

Ainda sobre as alterações climáticas globais, em 2007, foi realizada outra conferência, conhecida como Conferência de Bali, na Indonésia, para retomar as discussões das mudanças climáticas e propor novas metas e prazos para conter o avanço do aquecimento global.

As discussões em Bali determinaram que, em nível mundial, a emissão dos gases de efeito estufa, deve ter o seu pico na próxima década e a partir daí deve haver uma forte 
redução dos mesmos até ser atingido o valor mínimo de redução de 50\% em 2050, com base nas emissões de 1990.

Segundo as diretrizes de Bali, os países desenvolvidos devem liderar este processo e comprometerem-se internamente com margens de redução entre 25 a $40 \%$ até 2020 . Para tanto, o compromisso dos países desenvolvidos, como um grupo, deve reduzir as emissões em pelo menos 30\% até 2020 (em relação a 1990), com a completa descarbonização (reduções de mais de 85\%) até 2050.

Este encontro deu ênfase na utilização dos recursos tecnológicos para combater o aquecimento global. Nesse sentido, os países ricos precisam aumentar a transferência de fundos para a adaptação dos países em desenvolvimento. As principais medidas adotadas e que demonstram os avanços ocorridos nesta conferência, são:

- Criação de um novo Mecanismo de Desenvolvimento de Tecnologias Limpas, renováveis e eficientes;

- Criação de um Mecanismo de Redução de Desmatamento que forneça a escala e o financiamento necessários para reduzir drasticamente o desmatamento;

- Inclusão de todos os países do mundo no sistema de Quioto e, para os novos países industrializados, com alta renda per capita, como Coréia do Sul, Singapura e Arábia Saudita, fica determinada a obrigatoriedade por adotar metas com limite de emissões para o próximo período de compromissos, a partir de 2013.

De Quioto, no ano de 1997 até Bali, no ano de 2007, ocorreram algumas evoluções. O ponto positivo do encontro de Bali é que todos os países, sem exceção, terão que se esforçar no combate às mudanças climáticas. Todos os membros da convenção terão de adotar compromissos mensuráveis de corte de gases de efeito estufa. Esses compromissos vão desde ações de redução do desmatamento até programas que limitem o lançamento no ar de dióxido de carbono, metano e outros gases que contribuem para o aumento do efeito-estufa.

Todas as cúpulas sobre meio ambiente tem demonstrado o efetivo compromisso com a sustentabilidade, evidenciando as metas que os governos devem se pautar para buscar 
soluções para a crise ambiental pela qual o mundo vem passando. Nesse sentido, Born (2001:2) diz:

\begin{abstract}
Ao lidar com mudança de clima - uma temática, complexa por envolver questões de várias escalas (global, nacional, social e individual), dimensões (econômica, social, ambiental) e abordagens (política, científica, econômica), os profissionais de educação ambiental estarão contribuindo também para criar as capacidades (sociais, culturais e institucionais) necessárias para a implementação da convenção de clima e do Protocolo de Quioto. As mudanças de clima exigem dos cidadãos posturas corajosas, para a adoção de práticas que concretizem o ideário da sustentabilidade em cada lugar onde vivem, e em todos os lugares do mundo.
\end{abstract}

Assim, competem à sociedade civil, pesquisadores, governos e instituições públicas e privadas a identificação dos principais problemas e o estabelecimento de caminhos e metodologias para que o desenvolvimento sustentável seja atingido.

\title{
O Uso do Petróleo: Impactos e Benefícios
}

Queimar petróleo, tal como acontece com outros combustíveis fósseis, é a principal forma de contribuição para o aumento dos gases-estufa e dos problemas de poluição do ar. Entretanto, é praticamente impossível substituir por completo uma fonte de energia e de uma diversidade de produtos fabricados à sua base, por algo que ainda não possui pesquisas suficientes e nem mesmo possa garantir o mesmo sucesso, como são hoje os biocombustíveis.

A questão do aquecimento global e da superpopulação que hoje habita o planeta são temas que aliados à ampla utilização do petróleo, sua possibilidade de escassez devido ao fato de ser um recurso natural não-renovável, coloca em nível mundial a discussão sobre mudanças na matriz energética, conservação ambiental e desenvolvimento sustentável.

Para Stern (2006), o fluxo anual de dióxido de carbono e de outros gases que provocam o efeito estufa que aquece a atmosfera da Terra tem acelerado desde que o carvão, e, em seguida, o petróleo e o gás, começaram a fomentar a revolução industrial que proporcionou melhor qualidade de vida para as pessoas. Os bilhões de toneladas de dióxido de carbono e de outros gases-estufa que continuam se acumulando na frágil e protetora atmosfera terrestre já elevaram as concentrações para em torno de 430 partes por milhão (ppm) de dióxido de carbono $\left(\mathrm{CO}_{2}\right)$ equivalente, em comparação com 280 ppm antes da revolução industrial. 
Ainda para Stern (2006), as atividades humanas estão despejando 45 bilhões de toneladas de gases-estufa, principalmente o $\mathrm{CO}_{2}$, por ano na atmosfera, e essa quantidade está aumentando. Os ecossistemas terrestres são capazes de absorver cerca de metade dessas emissões, mas o resto é retido na atmosfera, aumentando a cada ano o estoque de gases acumulados.

As pesquisas sugerem que os esforços mundiais deveriam concentrar-se em limitar o nível final de gases-estufa na atmosfera para $450 \mathrm{ppm}$, conforme estabelecido nas conferências de Quioto e Bali.

Atingir essa meta é economicamente polêmico, mas reduzirá consideravelmente o risco de mudanças extremas de temperatura. Isso exige que reduzamos até 2050 o fluxo anual de emissões a pelo menos $25 \%$ dos níveis atuais, e que continuemos as reduções até que as emissões cheguem a cair para um nível de pelo menos $80 \%$ inferiores aos atuais, o que permitiria uma estabilização.

Os recentes estudos sobre mudanças climáticas dizem que há um risco de aumentar as temperaturas mundiais médias em mais de $5^{\circ} \mathrm{C}$ (equivalente à diferença entre hoje e a mais recente Idade do Gelo). Isso para Stern (2006) levaria a humanidade a um território desconhecido. Quanto mais alta a temperatura média, maior o risco de mudanças ecológicas irreversíveis e de uma multiplicação de impactos destrutivos.

\section{O Uso de Biocombustíveis: Impactos e Benefícios}

A pesquisa circunstanciada sobre os impactos ambientais do cultivo da cana-de-açúcar ainda são muito recentes, o que faz com que freqüentemente sejam fornecidas informações conflitantes, com números os mais diversos. Segundo a EMBRAPA (2008), no tocante aos impactos ambientais, o sistema agroindustrial da cana-de-açúcar deve ser divido em três subsistemas: o agrícola, o industrial e o de transporte.

Cada um destes subsistemas apresenta interações que variam no tempo, com o desenvolvimento e a introdução de novas tecnologias, e no espaço, conforme os solos, o relevo, o clima e o uso das terras. O impacto na atmosfera, com a troca de gases, apresenta múltiplas facetas, e o estudo isolado ou incompleto de cada uma delas tem contribuído para alimentar a polêmica sobre o fluxo de gases de efeito estufa emitidos pela cana. 
As metodologias para mensuração dos gases estufa ainda estão em debate, o que tem alimentado dúvidas sobe os modelos energéticos menos poluentes. Recentemente, duas pesquisas apresentaram resultados opostos no que se refere ao balanço de emissão de GEE para o sistema de produção de etanol. Searchinger (2008, p.1238) resume:

\begin{abstract}
Estudos anteriormente publicados encontraram que a substituição de gasolina por biocombustíveis reduz os gases do efeito estufa porque biocombustíveis seqüestram carbono por meio do crescimento do feedstock. Essas análises erraram ao não contar as emissões de carbono que ocorrem quando agricultores de todo o mundo respondem a preços maiores e convertem floresta e pastagens em novas áreas cultivadas para repor os grãos (ou a área plantada) desviados para biocombustíveis. Usando um modelo da agricultura mundial para estimar as emissões resultantes da mudança do uso do solo, nós encontramos que o etanol de milho, ao invés de produzir uma redução de $20 \%$ nas emissões, quase dobra as emissões de gases em 30 anos e aumenta as emissões durante 167 anos. Esses resultados trazem preocupações sobre a obrigação de adicionar percentuais de biocombustíveis em gasolina e enfatizam o valor do uso de resíduos.
\end{abstract}

Neste artigo, inclui-se nos cálculos do balanço de emissões o efeito indireto da produção de biocombustíveis sobre a mudança de uso do solo, que representa o deslocamento de culturas para áreas florestadas por conta da expansão da bioenergia.

Já de acordo com Macedo (2008), as emissões evitadas em 2002 por uso do etanol anidro e hidratado, corresponderam respectivamente a 2,6 e $1,7 \mathrm{t} / \mathrm{m}^{3} \mathrm{CO}_{2}$ equivalente. Tais dados referem-se ao etanol obtido a partir da cana-de-açúcar produzida na região centro-sul do Brasil.

Segundo este pesquisador, a emissão total de gás carbônico para a produção de etanol de cana em 2005/2006 foi de 417 quilos de gás carbônico equivalente por metro cúbico para o álcool hidratado, e de 436 quilos de gás carbônico equivalente por metro cúbico para o álcool anidro. Para 2020, a projeção é inferior, por conta de melhorias tecnológicas e ausência de queima - 330 quilos de gás carbônico equivalente por metro cúbico para hidratado e 345 quilos de gás carbônico equivalente por metro cúbico para anidro.

Estas diferenças de valores podem ser creditadas à grande quantidade de variáveis presentes no processo produtivo do etanol. $\mathrm{Na}$ análise das emissões de GEE em etanol são contabilizados o fluxo de carbono associados à emissão na sua produção, absorção durante o seu crescimento, e emissões decorrentes da colheita, transporte, na fabricação do álcool e queima nos motores dos veículos. 
Inclui-se ainda na contabilidade a emissão de gases provocada por mudanças no uso do solo por conta da expansão do cultivo da cana. Alguns países, como a Alemanha, defendem ser preciso medir e considerar o fato de a expansão da produção de cana poder expulsar outros cultivos, como os alimentares e de exportação, para áreas de florestas.

As discussões em torno das metodologias são vastas e ainda não estão no fim. Além destas controvérsias, há as diferenças relativas à matéria-prima do etanol: a cana-deaçúcar ou o milho.

Em relação ao etanol de cana, a emissão é de 0,4 tonelada de $\mathrm{CO}_{2}$ equivalente por metro cúbico de etanol anidro. No caso do etanol de milho, a emissão é de 1,9 tonelada. A diferença deve-se a maior quantidade de biomassa lignocelulósica presente na cana. Comparando-se com as emissões da gasolina, nota-se uma grande vantagem na utilização dos biocombustíveis, já que nesta última as emissões estão na faixa de 2 a 3 toneladas de $\mathrm{CO}_{2}$ equivalente por metro cúbico de gasolina. (MACEDO, 2008)

Outro ponto favorável aos biocombustíveis, é que o etanol usa o gás carbônico retirado da atmosfera pelas plantas, enquanto que os combustíveis fósseis, como os provenientes do petróleo, retiram o $\mathrm{CO}_{2}$ armazenado no solo, que não é posteriormente reabsorvido.

De qualquer forma, as reduções nas taxas de emissões de gases estufa observadas na produção e queima de biocombustíveis devem ser analisadas positivamente, já que a principal fonte para o aumento da concentração de dióxido de carbono na atmosfera desde o período pré-industrial é resultado do uso de combustível fóssil. De acordo com o $\operatorname{IPCC}(2007$, p.3)

\begin{abstract}
A concentração de dióxido de carbono, de gás metano e de óxido nitroso na atmosfera global tem aumentado marcadamente como resultado de atividades humanas desde 1750, e agora já ultrapassou em muito os valores da préindustrialização determinados através de núcleos de gelo que estendem por centenas de anos. O aumento global da concentração de dióxido de carbono ocorre principalmente devido ao uso de combustível fóssil e a mudança no uso do solo, enquanto o aumento da concentração de gás metano e de óxido nitroso ocorre principalmente devido à agricultura.
\end{abstract}

Em relatório publicado pela International Energy Agency (OECD/IEA, 2006:11), estima-se que o Brasil reduziu suas emissões de dióxido de carbono em aproximadamente 574 milhões de toneladas desde 1975, equivalente a $10 \%$ das 
emissões do país durante este período, em função da utilização do álcool como combustível de veículos.

Após a afirmação do relator da Organização das Nações Unidas para o Direito à Alimentação, Jean Ziegler, de que o etanol seria "crime contra a humanidade", por inflacionar os preços dos alimentos, cresceram as atenções dos países sobre o impacto das plantações de biocombustíveis sobre a produção de alimentos.

O comissário da ONU pediu que a União Européia abandonasse sua meta de ter $10 \%$ dos carros movidos a etanol até 2020, enquanto que alguns países, como a França, usaram a alta dos preços para defender medidas protecionistas na agricultura e até o fim da expansão do etanol.

Ziegler apresentou dados do International Food Policy Research Institute (ROSEGRANT, 2008), que afirmam ser a crescente demanda por biocombustíveis durante o período de 2000 a 2007, a responsável por um aumento estimado de $30 \%$ no preço médio dos grãos. A maior alta se deu no preço do milho (39\%), enquanto que para o arroz e o trigo os aumentos foram respectivamente de 21 e $22 \%$. Ainda segundo o comissário, um aumento de $1 \%$ nos preços de alimentação adiciona 16 milhões de pessoas entre a população desnutrida.

Previsões do International Food Policy Research Institute, mostram que, se os preços do petróleo continuarem subindo, o que parece ser a tendência, os preços de importantes produtos agrícolas se elevarão em proporções bastante significativas. (SILVA, 2007).

Estas críticas precisam ser analisadas sob diversas perspectivas. Inicialmente, há que se observar a diferença entre a matéria-prima do etanol - cana-de-açúcar ou milho plantados respectivamente no Brasil e EUA, maiores produtores mundiais de etanol. Os países da Europa produzem biocombustíveis de commodities agrícolas como milho, óleos vegetais (soja, palma e colza), mas em quantidades pequenas, por causa principalmente da falta de área agricultável.

O etanol de milho de fato concorre com a alimentação, já que $25 \%$ da colheita de milho americana será consumida na produção de etanol, reduzindo as exportações e elevando o preço da commodity, que é uma das principais bases das rações animais. Os Estados Unidos produziram em 2005, 44,5\% do etanol mundial, a partir do milho. A projeção é 
de que no final de 2008, a produção praticamente triplique, passando de 4,3 bilhões de galões anuais para 11,4 bilhões (SILVA, 2007).

A área necessária para o plantio provavelmente irá aumentar, já que a produtividade do etanol do milho é pequena, se comparada a do etanol de cana. Segundo Andreoli (2006), a cana produz três vezes mais álcool por área do que o milho.

Pode ocorrer que o plantio de biocombustíveis "empurre" lavouras de alimentos para outras regiões, o que não é necessariamente negativo. Atualmente, calcula-se que a Terra é formada por aproximadamente 14,9 bilhões de hectares de terras emersas, mas apenas $20 \%$ disso - cerca de 3 bilhões de hectares - podem ser cultivados (VERLI, 2007). O resto é ocupado por desertos, cordilheiras, geleiras etc. E atualmente apenas metade da área cultivável - 1,5 bilhões de hectares - é de fato cultivada.

Para substituir toda a gasolina consumida hoje por etanol, seriam necessários 857 milhões de hectares ocupados por milho ou 427 milhões de hectares de cana. Teoricamente, haveria ainda muito espaço para a plantação de alimentos. No entanto, muitas dessas regiões são ocupadas por florestas, savanas e outros ecossistemas e sua ocupação resultaria em diversos problemas, como perda da biodiversidade, desertificação e enfraquecimento do solo.

O efeito advindo poderia ser o inverso do que se espera ao utilizar biocombustíveis: ao invés de minimizar o aquecimento global por redução de emissões de gases estufa, acabaria havendo maiores alterações nos padrões climáticos globais.

Os problemas relacionados à crise alimentar não tem no etanol de cana seu grande vilão. O Brasil, por exemplo, tem 180 milhões de hectares de pastagens, dos quais 71 milhões são cultiváveis. E destes, só 22 milhões são próprios para cana. Ou seja, ainda restam 49 milhões de hectares para alimentos. Segundo dados da Conab (2007), na safra de 2007/2008, a área plantada com cana-de-açúcar cresceu 12,3\% em relação à da safra anterior. A cana ocupou $0,4 \%$ da área total cultivada com grãos. Neste mesmo período, a safra de grãos aumentou $6,8 \%$.

Os fatores que levaram à inflação dos alimentos provavelmente têm outras origens. Marcelo Gingale, do Banco Mundial, apontou cinco fatores atuando em escala mundial: o aumento da produção de biocombustíveis e a manutenção dos respectivos subsídios 
em países ricos, como os EUA; o incremento dos custos com a alta do petróleo e dos fertilizantes; o aumento do consumo em países como China, Índia e Brasil; o mau tempo e a quebra de safras em vários países; e a crise financeira com origem nos EUA, que levou investidores a apostar em contratos de bolsas de mercadorias (ISTO É DINHEIRO, 2008).

Além disso, deve-se considerar que os preços das matérias primas agrícolas correspondem a apenas $20 \%$ do custo médio da comida. O restante fica por conta da mão-de-obra, do transporte e de outros custos, como embalagem. Dados da FAO indicam também que de 40 a $60 \%$ da produção agrícola mundial é perdida por falta de armazenamento adequado, o que certamente encarece o produto final.

A cana-de-açúcar é uma das culturas de produção intensa que consome relativamente poucos recursos naturais no local onde é plantada, mas introduz no meio ambiente novos elementos e produtos causadores de desequilíbrios (inseticidas, pesticidas, fertilizantes, sais etc.). A figura abaixo exemplifica as diversas dimensões envolvidas.

Figura 1: Dimensões envolvidas nos impactos do plantio da cana-de-açúcar.

\begin{tabular}{|l|l|l|l|}
\hline \multicolumn{3}{|c|}{ IMPACTOS NA ATMOSFERA } \\
\hline $\begin{array}{l}1 \\
\text { Fases do Cultivo }\end{array}$ & Plantio ou Rebrota & \multicolumn{1}{|c|}{ Crescimento } & \multicolumn{1}{c|}{ Colheita } \\
\hline $\begin{array}{l}\text { Principais } \\
\text { Operaçôes }\end{array}$ & $\begin{array}{l}\text { Preparo do Solo e/ou } \\
\text { Reforma de Plantio }\end{array}$ & Tratos Culturais & $\begin{array}{l}\text { Colheita Manual ou } \\
\text { Colheita Mecânica }\end{array}$ \\
\hline $\begin{array}{l}\text { Técnicas e } \\
\text { Tecnologias }\end{array}$ & $\begin{array}{l}\text { Corretivos } \\
\text { Vintilizantes } \\
\text { Restos Culturais }\end{array}$ & $\begin{array}{l}\text { Controle Biológico } \\
\text { Inseticidas }\end{array}$ & $\begin{array}{l}\text { Cana Queimada ou } \\
\text { Cana Crua }\end{array}$ \\
\hline \multicolumn{4}{|l|}{} \\
\hline
\end{tabular}

Fonte: EMBRAPA, 2008

O impacto varia muito nos diferentes meios físicos, mas pode-se afirmar que o maior deles observa-se exatamente no solo. A tabela 1 apresenta uma classificação dos tipos de impactos provocados no solo pela cana-de-açúcar. 
Tabela 1: Impacto do plantio da cana-de-açúcar sobre o solo

\begin{tabular}{|c|c|c|c|c|}
\hline $1-$ Nenhum & $2-$ Baixo & 3-Médio & $4-$ Alto & 5-Altíssimo \\
\hline \multicolumn{3}{|c|}{ Conservação } & \multicolumn{2}{|l|}{5} \\
\hline \multicolumn{2}{|c|}{ Recobrimento } & & \multicolumn{2}{|c|}{5} \\
\hline \multicolumn{2}{|c|}{ Adensamento } & & \multicolumn{2}{|c|}{4} \\
\hline \multicolumn{2}{|c|}{ Perda } & & \multicolumn{2}{|c|}{3} \\
\hline \multicolumn{2}{|c|}{ Sais } & & \multicolumn{2}{|c|}{2} \\
\hline \multicolumn{2}{|c|}{ Biológicos } & & \multicolumn{2}{|c|}{1} \\
\hline \multicolumn{2}{|c|}{ Agrotóxicos } & & \multicolumn{2}{|c|}{1} \\
\hline
\end{tabular}

Fonte: EMBRAPA, 2008

Uma das alternativas utilizadas para minimizar os impactos e impedir que o solo fique descoberto, e conseqüentemente haja perdas de solo por erosão no período de renovação dos canaviais, é a plantação de leguminosas em regime de rotação com a cana. Além disso, há pesquisas sobre o controle biológico de pragas, em especial a cigarrinha, por meio de fungos, para controle sem utilização de defensivos químicos.

Um grande problema refere-se ao alto volume de vinhaça produzido - de 12 a 13 litros para cada litro de álcool. Muitas usinas aplicam a vinhaça por aspersão como uma fertirrigação devido a sua riqueza de potássio, mas como estão há muitos anos no mesmo local, esses solos normalmente já estão muito saturados e podem ocorrer perdas de elementos químicos por lixiviação, atingindo o lençol freático.

Outro resíduo da cana, mas neste caso na produção do açúcar, é a torta de filtro, material orgânico muito utilizado para melhorar a fertilidade dos solos e a produtividade da cana. Este composto está sendo estudado para melhorar a fertilidade e conseqüente produtividade de solos marginais, o que permitirá liberar áreas melhores para outras culturas alimentícias e, ao mesmo tempo, evitar o desmatamento de novas áreas.

Sob o aspecto do consumo de água, deve-se salientar que a lavoura de cana necessita mais ou menos $400 \ell$ para produzir $1 \mathrm{~kg}$ de matéria seca, valor similar a outras culturas como a soja. O grande consumo de água encontra-se, entretanto, no processo industrial. Uma usina que processa, por exemplo, 1 milhão de ton/ano consome aproximadamente $300 \mathrm{~m}^{3}$ de água por hora. Se a jornada for de $10 \mathrm{~h} /$ dia, teremos um consumo de 3.000 $\mathrm{m}^{3} /$ dia. E há que se considerar ainda que o pico de funcionamento das usinas se dá justamente na época da seca, onde a vazão dos cursos d'água tende geralmente a reduzir. 


\section{Prognóstico em relação ao consumo de derivados de petróleo, emissões de $\mathrm{CO}_{2}$ e plantio de reflorestamentos}

Toribaté, com seu transporte, indústrias, agronegócios e comércios, apresenta um consumo de petróleo semelhante ao da média mundial, de cerca de $1,057 \mathrm{t} \mathrm{CO}_{2} /$ pessoa $\mathrm{x}$ ano. Este valor é calculado a partir da emissão de $\mathrm{CO}_{2}$ proveniente da queima diária de $70 \%$ do petróleo consumido mundialmente, 85 milhões de barris, dividido pela população mundial estimada em 6,5 bilhões de pessoas. Considerando sua população, infere-se que anualmente são emitidas no município 617 mil t $\mathrm{CO}_{2}$. O crescimento populacional é o mesmo da média mundial, de $0,72 \%$ ao ano.

O município, embora inserido em um país em desenvolvimento - portanto não sujeito às reduções impostas pelo tratado de Quioto - estima que a qualidade de vida de seus habitantes está se deteriorando e procura alternativas para mitigar as emissões de carbono e tornar-se uma cidade sustentável.

Além disso, já está procurando se adaptar às recomendações propostas em Bali (2007), a serem discutidas na renegociação de Quioto, em 2012. Segundo estas novas diretrizes, todos os países fora do Anexo 1, devem reduzir suas emissões em até $50 \%$ até 2050 , e cessar os desmatamentos.

Entre as alternativas sugeridas, destaca-se a preservação de florestas nativas, a recuperação de áreas degradadas e a implantação de reflorestamentos que têm a propriedade de absorver $\mathrm{CO}_{2}$ pela fotossíntese e fixá-lo em forma de matéria lenhosa.

Este mecanismo de seqüestrar carbono foi lançado na Convenção Quadro das Nações Unidas sobre Mudança de Clima, em 1992, e mais tarde adotado em Quioto como um instrumento de flexibilização dos compromissos de redução das emissões de GEE dos países com metas de redução.

Para avaliar se a opção dos reflorestamentos atende às necessidades do desenvolvimento socioambiental da cidade, temos que considerar algumas proposições. A primeira diz respeito ao tipo de planta utilizada para a fixação do carbono. O total de carbono armazenado reflete o balanço a longo prazo entre a absorção da planta, a fixação de carbono no solo e as perdas por respiração e decomposição. Os valores para espécies vegetais diversas e em regiões também diversas, apresentam grandes variações. 
Neste trabalho, para efeito de simulação considera-se uma árvore média, que após 20 anos de crescimento atinge a altura máxima de $16 \mathrm{~m}$; possui diâmetro de $28 \mathrm{~cm}, 12 \%$ de umidade e teor da base seca (Carbono) de 50\%.

Supondo que a árvore cresça a uma taxa constante de $1 / 20$ por ano, o $\mathrm{CO}_{2}$ absorvido anualmente será de $0,0278 \mathrm{t}$.

Como a diretriz de Bali sugere uma redução de 50\% das emissões até 2050, a partir do ano base 2012, na tabela 1 é sugerido um prognóstico de quantas árvores terão que ser plantadas anualmente e qual será a área ocupada por elas. São feitas duas projeções diferentes de emissão de $\mathrm{CO}_{2}$ : uma traz os valores crescentes, sem seguir a meta de redução. Outra coluna apresenta os dados de emissão, caso o município resolva adotar a meta de redução de $50 \%$ até 2050 .

Nesta situação, as árvores começariam a ser plantadas em 2009. O número de árvores a serem plantadas foi calculado segundo a seguinte equação:

\section{Árvores a serem plantadas $=[(S-C) / 0,0278]-$ árvores plantadas nos últimos 20 anos}

Onde:

$$
\begin{array}{lll}
S & = & \text { Emissão de } \mathrm{CO}_{2} \text { sem meta de redução } \\
\mathrm{C} & = & \text { Emissão de } \mathrm{CO}_{2} \text { com meta de redução de } 50 \% \\
0,0278= & \text { toneladas de } \mathrm{CO}_{2} \text { absorvidas por árvore/ano }
\end{array}
$$

A área para plantio foi estimada considerando-se que cada árvore ocupa em média $4 \mathrm{~m}^{2}$. Foram consideradas as árvores plantadas somente nos últimos 20 anos, pois após este período elas deixam de crescer e portanto de absorver $\mathrm{CO}_{2}$.

Tabela 2: Prognóstico do plantio de árvores em Toribaté, de 2008 a 2050

\begin{tabular}{c|c|c|c|c|c}
\hline \multirow{2}{*}{ ano } & população & $\begin{array}{c}\text { emissão } \mathrm{CO}_{2} \\
\text { (t/ano) }\end{array}$ & $\begin{array}{c}\text { emissão } \mathrm{CO}_{2} \\
\text { (t/ano) }\end{array}$ & árvores/ano & \multirow{2}{*}{$\mathrm{km}^{2} /$ ano } \\
\cline { 3 - 5 } & & sem meta de redução & com meta de redução & & \\
\hline 2008 & 583.810 & 617.087 & 617.087 & 0 & 0,0 \\
\hline 2009 & 588.013 & 621.530 & 606.987 & 523.148 & 2,1 \\
\hline 2010 & 592.247 & 626.005 & 597.052 & 518.352 & 2,1 \\
\hline 2011 & 596.511 & 630.512 & 587.279 & 513.661 & 2,1 \\
\hline 2012 & 600.806 & 635.052 & 577.666 & 509.075 & 2,0 \\
\hline 2029 & 678.737 & 717.425 & 436.347 & 445.666 & 1,8 \\
\hline 2050 & 789.099 & 834.078 & 308.544 & 844.829 & 3,4 \\
\hline & & total & 29.014 .800 & 116,1 \\
& & &
\end{tabular}


Com auxílio da tabela acima, percebe-se que, se nenhuma árvore for derrubada, 116,1 $\mathrm{km}^{2}$ de área serão necessários para receber o reflorestamento que deverá absorver todo o gás carbônico emitido pela população de Toribaté até 2050. Nota-se também que em 2029 terão passados 20 anos desde o início do plantio de árvores, o que significa que as primeiras deixarão de cumprir sua função de seqüestradoras de $\mathrm{CO}_{2}$.

Uma proposta é a de que após este período as árvores sejam cortadas, e sua madeira utilizada para alguma finalidade que não a queima, que liberaria novamente para o ar o carbono estocado. Pode-se usá-la para construir bens duráveis como móveis ou casas, gerando recursos que poderiam ser reaplicados na conservação da floresta.

Se esta idéia for levada adiante, $40 \mathrm{~km}^{2}$ serão necessários para manter a floresta ativa. Esta área representa somente 4,0\% da área rural e 3,1\% da área total do município.

\section{Prognóstico em relação ao plantio de Biocombustíveis}

Entre as formas de bioenergia, o etanol apresenta o melhor balanço possível. O cultivo da cana-de-açúcar retira da atmosfera quase todo o dióxido de carbono que a produção e o uso do etanol emitem. Estudos indicam que são emitidos $400 \mathrm{~kg} \mathrm{CO}_{2}$ equivalente por metro cúbico de etanol anidro produzido, enquanto que a gasolina libera cerca de 3400 $\mathrm{kg}$ (MACEDO, 2008).

Sob este aspecto, parece interessante que os governos locais incentivem o seu plantio. No entanto, a área necessária para a cana deve ser tal que não impeça o plantio de outras culturas destinadas à alimentação de homens e animais, e nem de pastagens.

Para avaliar qual seria o impacto de substituir todo o combustível fóssil dos veículos de Toribaté por etanol, calcularemos qual seria a emissão de $\mathrm{CO}_{2}$ resultante. Temos que lembrar que o rendimento médio de um veículo a álcool é cerca de $37 \%$ menor do que de um a gasolina e $66 \%$ menor do que o a diesel. 
Tabela 3: Emissão de $\mathrm{CO}_{2}$ veicular em Toribaté por queima de etanol (2008)

\begin{tabular}{|c|c|c|c|c|c|c|c|}
\hline $\begin{array}{c}\text { Veículos } \\
\left(\mathrm{n}^{0}\right)\end{array}$ & Tipo & $\begin{array}{l}\text { Consumo } \\
\text { de etanol } \\
(\mathrm{km} / \ell \mathrm{e} \\
\ell / \mathrm{km})\end{array}$ & $\begin{array}{c}\text { Distância } \\
\text { percorrida } \\
(\mathrm{km} / \mathrm{dia})\end{array}$ & $\begin{array}{c}\text { Consumo } \\
\text { de etanol } \\
\text { ( } \ell / \text { dia })\end{array}$ & $\begin{array}{l}\text { Emissão } \\
\text { por } \\
\text { queima } \\
\text { de } \\
\text { etanol }\end{array}$ & $\begin{array}{c}\text { Emissão } \\
(\mathrm{kg} \\
\left.\mathrm{CO}_{2} / \mathrm{dia}\right)\end{array}$ & $\begin{array}{c}\text { Emissão } \\
(\mathrm{t} \\
\left.\mathrm{CO}_{2} / \mathrm{ano}\right)\end{array}$ \\
\hline \multirow{3}{*}{103.570} & $\begin{array}{c}75 \% \\
\text { passeio }= \\
77.678\end{array}$ & $8(0,125)$ & \multirow[t]{2}{*}{5} & 48.549 & \multirow{3}{*}{$\begin{array}{l}400 \mathrm{~kg} \\
\mathrm{CO}_{2} / \\
1000 \ell \\
\text { etanol }\end{array}$} & 19.420 & $7,1.10^{3}$ \\
\hline & $\begin{array}{l}15 \% \text { Moto } \\
=15.535\end{array}$ & $\begin{array}{c}22 \\
(0,045)\end{array}$ & & 3.495 & & 1.398 & $0,51.10^{3}$ \\
\hline & $\begin{array}{c}10 \% \\
\text { Transporte } \\
=10.357\end{array}$ & $\begin{array}{c}2,6 \\
(0,38)\end{array}$ & 50 & 196.783 & & 78.716 & $28,7.10^{3}$ \\
\hline \multirow{2}{*}{\multicolumn{4}{|c|}{ TOTAL }} & $\begin{array}{c}248.827 \\
(\ell / d i a)\end{array}$ & & & $36,3 \cdot 10^{3}$ \\
\hline & & & & 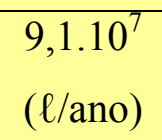 & & & \\
\hline
\end{tabular}

Fonte: Dados da pesquisa

Considerando que a safra da cana-de-açúcar é anual, e que com 1 hectare $\left(1.10^{-2} \mathrm{~km}^{2}\right)$ de terra se consegue produzir $7.500 \ell$ de etanol (ANDREOLI, 2006), estima-se que para atender toda a demanda de consumo dos veículos de Toribaté sejam necessários 121 $\mathrm{km}^{2}$ de terra. Para atender as diretrizes de Bali serão pois necessários, até 2050, 60,5 $\mathrm{km}^{2}$ de terra para a cultura da cana-de-açúcar.

Este valor não é desprezível, mas talvez não tenha impacto na produção de alimentos ou na criação de gado, pois o município tem área rural de $1000 \mathrm{~km}^{2}$. Se aplicarmos à cidade em estudo a média mundial de área agricultável (VERLI, 2007) de 20\%, teríamos $200 \mathrm{~km}^{2}$ disponíveis para culturas em geral. Ao retirarmos o necessário para o plantio da cana, ainda sobrariam $139,5 \mathrm{~km}^{2}$, ou seja, a cana-de-açúcar ocuparia $30,2 \%$ da terra apta aos agronegócios. 


\section{Propostas de Ações}

Analisando-se os impactos da plantação de reflorestamentos e de cana-de-açúcar, algumas ações são propostas para que Toribaté atinja um patamar que a torne sustentável sob o ponto de vista sócio-ambiental.

A primeira delas é a de aproveitar a substituição do combustível fóssil por renovável nos veículos da cidade, e vender Certificados de Redução de Emissões (CREs), previstos no Protocolo de Quioto. Trata-se de uma das modalidades presentes nos Mecanismos de Desenvolvimento Limpo - MDL (FRANGETTO, 2002), que buscam a compensação e redução de emissão de GEE para mitigar mudanças climáticas.

Esse mecanismo possibilita aos países desenvolvidos que tem o compromisso de reduzir os gases de efeito estufa, adquirir em projetos gerados em países em desenvolvimento os CREs, como maneira de cumprir parte de seus compromissos, ou que esses países financiem projetos em países em desenvolvimento de forma que o país doador dos recursos financeiros fique com os créditos para a emissão de GEE.

Dessa maneira, o MDL contribui para que sejam realizados investimentos em países Não-Anexo 1 e, concomitantemente, ajuda os países Anexo 1 a cumprirem suas metas de redução. Os investimentos realizados nos países Não-Anexo 1 devem contribuir para o desenvolvimento sustentável, de acordo com os objetivos do MDL.

Embora Toribaté não esteja inserida em um país do Anexo 1, e portanto sujeita às condicionantes de redução de emissões de Quioto, é nestes países que os do Anexo 1 encontram, em geral, as condições reais de compensação da sua emissão de GEE. Surgem, assim, duas situações:

- A de países Não-Anexo 1 (como o Brasil) serem demandados ao seqüestro de carbono e obterem recursos econômicos e satisfação das diretrizes globais de redução da poluição pelos países desenvolvidos (financiadores).

- Os administradores locais dos países Não-Anexo 1 se adiantarem em relação às diretrizes de Bali, iniciando projetos de redução de emissões ou de seqüestro de carbono. 
Um dos projetos a ser apresentado é de emissões evitadas, a partir da troca dos motores dos veículos da cidade, que gradualmente passariam a rodar com etanol de cana. Este projeto seria negociado com os países do Anexo 1 que têm dificuldade em atingir suas metas de redução. Em maio deste ano, os CREs para entrega em dezembro de 2008 estavam cotadas a 17,68 euros a tonelada evitada de dióxido de carbono (MERCADOS, 2008).

Para se determinar qual seria o valor arrecadado com a venda dos certificados, é necessário calcular qual seria a emissão de $\mathrm{CO}_{2}$ evitada ao se substituir o combustível fóssil pelo etanol nos veículos de Toribaté.

No município há 103.570 unidades veiculares, das quais $75 \%$ são automóveis de passeio movidos a gasolina, gás natural veicular (GNV), diesel e/ou álcool, 15\% são motocicletas movidas à gasolina e 15\% são veículos de transporte (caminhões e ônibus) movidos a diesel.

Entre os automóveis, 57\% rodam a base de gasolina, 5\% com GNV, 18\% com diesel e $20 \%$ com álcool. Estes valores são equivalentes aos de outras cidades brasileiras de porte semelhante.

As emissões de $\mathrm{CO}_{2}$ por tipo de veículo possuem inúmeras variáveis, entre elas a idade e conservação dos veículos e a velocidade média com que o veículo é conduzido. Neste trabalho, para cálculo do balanço de massa, considerou-se o consumo de combustível, a distância percorrida, a densidade do combustível e o teor de carbono no combustível, segundo a equação abaixo:

$$
\text { Emissões }\left(\mathrm{kg} \text { de } \mathrm{CO}_{2}\right)=C C \times \mathrm{DP} \times \mathrm{DC} \times \mathrm{TC} \times 3,6
$$

Onde: $\quad C C=$ consumo de combustivel $\left(\mathrm{m}^{3} / \mathrm{km}\right)$

$$
\begin{aligned}
& D P=\text { distância percorrida }(\mathrm{km}) \\
& D C=\text { densidade do combustível }\left(\mathrm{kg} / \mathrm{m}^{3}\right) \\
& T C=\text { teor de carbono no combustivel }(\%)
\end{aligned}
$$

O número 3,6 se refere ao fator de conversão do teor de carbono para $\mathrm{CO}_{2}$, pois a massa do $\mathrm{CO}_{2}$ é de 44 enquanto que a do carbono é de 12. Logo, 44/12=3,6. Como o 
consumo varia com a potência, e a maioria dos automóveis têm potência entre 1,0 e 2,0, considerou-se a potência média de 1,5.

O resultado destes cálculos é apresentado nas tabelas 4 e 5. Os automóveis a álcool não foram computados por já serem movidos a combustível renovável.

Tabela 4: Emissão de $\mathrm{CO}_{2}$ para carros de passeio, caminhonetes e motocicletas, movidos a combustível fóssil.

\begin{tabular}{c|c|c|c|c}
\hline Combustível & $\begin{array}{c}\text { Teor de } \\
\text { carbono }(\%)\end{array}$ & $\begin{array}{c}\text { Densidade } \\
(\mathrm{kg} / \ell)\end{array}$ & $\begin{array}{c}\text { Consumo } \\
(\mathrm{km} / \ell \mathrm{e} \\
\ell / \mathrm{km})\end{array}$ & $\begin{array}{c}\text { Emissões } \\
\left(\mathrm{kg} \mathrm{CO}_{2} / \mathrm{km}\right)\end{array}$ \\
\hline Gasolina* & 0,67 & 0,74 & $11(0,091)$ & 0,162 \\
\hline GNV & 0,75 & 0,85 & $11(0,091)$ & 0,209 \\
\hline Diesel & 0,84 & 0,85 & $10(0,1)$ & 0,257 \\
\hline Moto/gasolina* & 0,67 & 0,74 & $30(0,033)$ & 0,0589 \\
\hline
\end{tabular}

* com adição de $20 \%$ de etanol

Fonte: Agência Nacional do Petróleo (ANP) disponível em www.anp.gov.br

Tabela 5: Emissão de $\mathrm{CO}_{2}$ para ônibus e caminhões (Transporte)

\begin{tabular}{c|c|c|c|c}
\hline Combustível & $\begin{array}{c}\text { Teor de } \\
\text { carbono (\%) }\end{array}$ & $\begin{array}{c}\text { Densidade } \\
(\mathrm{kg} / \ell)\end{array}$ & $\begin{array}{c}\text { Consumo } \\
(\mathrm{km} / \ell \mathrm{e} \\
\ell / \mathrm{km})\end{array}$ & $\begin{array}{c}\text { Emissões } \\
\left(\mathrm{kg} \mathrm{CO}_{2} / \mathrm{km}\right)\end{array}$ \\
\hline Diesel & 0,84 & 0,85 & $4(0,25)$ & 0,643 \\
\hline
\end{tabular}

Fonte: Agência Nacional do Petróleo (ANP) disponível em www.anp.gov.br

Obtida a emissão relativa a cada veículo e combustível, estimou-se a distância média que cada veículo percorre e determinou-se a emissão total proveniente da queima de combustível fóssil. 
Tabela 6: Emissão de $\mathrm{CO}_{2}$ veicular em Toribaté por queima de combustíveis fósseis (2008)

\begin{tabular}{|c|c|c|c|c|c|c|}
\hline $\begin{array}{l}\text { Veículos } \\
\text { (unidades) }\end{array}$ & Tipo & Combustível & $\begin{array}{c}\text { Distância } \\
\text { percorrida } \\
(\mathrm{km} / \mathrm{dia})\end{array}$ & $\begin{array}{c}\text { Emissão } \\
(\mathrm{kg} \\
\left.\mathrm{CO}_{2} / \mathrm{km}\right)\end{array}$ & $\begin{array}{c}\text { Emissão } \\
(\mathrm{kg} \\
\left.\mathrm{CO}_{2} / \text { dia }\right)\end{array}$ & $\begin{array}{c}\text { Emissão } \\
(\mathrm{t} \\
\left.\mathrm{CO}_{2} / \text { ano }\right)\end{array}$ \\
\hline \multirow{5}{*}{103.570} & \multirow{3}{*}{$\begin{array}{c}75 \% \\
\text { passeio } \\
=77.678\end{array}$} & $\begin{array}{c}57 \% \\
\text { gasolina }= \\
44.276\end{array}$ & \multirow{4}{*}{5} & 0,162 & 35.864 & $13,1.10^{3}$ \\
\hline & & $\begin{array}{c}5 \% \mathrm{GNV} \\
=3.884\end{array}$ & & 0,209 & 4.059 & $1,5.10^{3}$ \\
\hline & & $\begin{array}{c}18 \% \text { diesel } \\
=13.982\end{array}$ & & 0,57 & 39.849 & $14,5 \cdot 10^{3}$ \\
\hline & $\begin{array}{c}15 \% \\
\text { motos } \\
=15.535\end{array}$ & Gasolina & & 0,0589 & 4.575 & $1,7.10^{3}$ \\
\hline & \multicolumn{2}{|c|}{$10 \%$ transporte $=10.357$} & 50 & 0,643 & $80.10^{3}$ & $121.10^{3}$ \\
\hline & & & & & TOTAL & $151,8.10^{3}$ \\
\hline
\end{tabular}

Fonte: Dados da pesquisa

Nesta tabela foram desconsiderados os $20 \%$ de veículos de passeio que rodam com etanol.

Pelos cálculos efetuados na tabela 6, temos que a emissão total em 2008 dos veículos movidos a combustível fóssil em Toribaté será de 152 mil toneladas de $\mathrm{CO}_{2}$.

A tabela 3, de emissão de $\mathrm{CO}_{2}$ veicular em Toribaté por queima de etanol (2008), nos apresenta um resultado de 36,3 mil toneladas de $\mathrm{CO}_{2}$. Descontados os carros a álcool, serão emitidas 34,9 mil toneladas de $\mathrm{CO}_{2}$.

Assim, se todo o combustível fóssil utilizado nos veículos de Toribaté fosse substituído por etanol de cana, seria evitada anualmente a emissão de 116,9 mil toneladas de $\mathrm{CO}_{2}$. Este montante vendido pela cotação dos CREs geraria recursos da ordem de $€ 2$ milhões, ou cerca de R 5 milhões. 
A segunda alternativa de venda de créditos de carbono se refere ao projeto de retenção de carbono nos reflorestamentos. A sugestão para Toribaté é de plantação de árvores a partir de 2009. As quantidades de árvores a serem plantadas variam ano a ano, conforme explicitado na tabela 1, mas tomando-se como parâmetro o ano de 2009, no qual serão plantadas 523 mil árvores, e a cotação atual da tonelada de $\mathrm{CO}_{2}$, de $€ 17,68$, é possível obter recursos de cerca de $€ 257$ mil por ano, ou R $\$ 650$ mil.

Os administradores locais precisam estar atentos ao fato que de, obviamente tanto a mudança dos motores dos veículos quanto a plantação das árvores tem de ser realizada gradualmente e, portanto, também os recursos serão transferidos em longo prazo.

\section{CONSIDERAÇÕES FINAIS}

A utilização da aritmética ambiental oferece aos administradores locais subsídios valiosos para a tomada de decisões, na medida em que permite expor através de números, as tendências, projeções, custos e prazos das ações a serem realizadas. Facilita assim, que os projetos sejam baseados em dados e não suposições.

Neste artigo, ao compararmos emissões provenientes da queima de combustíveis fósseis e renováveis emitidos por veículos - com o intuito de sugerir alternativas para conter os efeitos do aquecimento global e atender as diretrizes propostas nas cúpulas de Quioto e Bali - pudemos calcular as áreas necessárias de plantio de florestas e cana-de-açúcar. Isto colabora para se avaliar com mais eficiência as propostas de mitigação dos impactos em um município padrão, e extrapolar estes dados a outras localidades semelhantes.

Foi possível demonstrar que - se a redução de emissão de GEE for perseguida por substituição do combustível fóssil por etanol - extensas áreas deverão ser destinadas ao cultivo de cana-de-açúcar ou outros vegetais. As conseqüências podem ser eventuais restrições ao cultivo de alimentos, seguidas de inflação, sem contar outros impactos inerentes a uma monocultura intensiva, como por exemplo, a perda da biodiversidade.

Identificou-se na cana-de-açúcar uma fonte relativamente limpa de energia, ainda mais se comparada aos combustíveis fósseis, que emitem quantidades bem mais impactantes de gases de efeito estufa. A cana, entretanto, não deve ser considerada opção única e exclusiva, mas, em conjunto com o biodiesel, ser utilizada como fonte provisória e 
alternativa, enquanto é melhorado o aproveitamento de outras fontes renováveis, como a energia solar, a eólica e o hidrogênio.

É imprescindível ainda que outras ações sejam associadas, como o aumento do rendimento dos motores de transformação energética, combate aos desperdícios e adoção de melhores tecnologias e sistemas para o setor de transportes e processos produtivos de modo geral.

Um entrave para se chegar a uma cidade sustentável é certamente o alto custo associado às mudanças que devem ser realizadas. Nesse sentido, a participação e atuação da população e dos governos locais é indispensável, e as propostas de flexibilização existentes nos MDL, com o comércio de emissões por créditos de carbono, oferece alternativas para uma transição economicamente viável.

\section{REFERÊNCIAS}

ANDREOLI, C.; SOUZA, S.P. de. Cana-de-açúcar: a melhor alternativa para conversão da energia solar e fóssil em etanol. Economia e Energia, Rio de Janeiro, n. 59, p. 27-33, dez. 2006.

BORN, R. Transformações globais e mudanças de clima. Disponível em: $<$ www.vitaecivilis.org.br/default.asp?site_Acao=MostraPagina\&paginaId=1654> Acesso em: maio 2008.

CONAB (Companhia Nacional de Abastecimento), Acompanhamento da Safra Brasileira Cana-de-açúcar Safra 2007/2008, segundo levantamento, agosto/2007, Brasília

EMBRAPA, Monitoramento por Satélite. Impacto Ambiental da Cana-de-Açúcar. Disponível em: $<$ http://www.cana.cnpm.embrapa.br/setor.html.> Acesso em: maio 2008.

FEHR, M., Toribaté 2008. Disponível em: $<$ http://www.manfred.triang.net/toribate2008.rtf $>$ Acesso em: maio 2008.

FRANGETTO, F. e GAZANI, F.R., Viabilização Jurídica do Mecanismo de Desenvolvimento Limpo (MDL) no Brasil: O Protocolo de Quioto e a cooperação internacional. Ed. Fundação Perirópolis, 2002.

GARDNER, G. Do Rio a Johanesburg - Conscientização crescente, reação arrastada. Disponível em: $<$ http://www.ambientebrasil.com.br/composer.php3?base=./gestao/index.html\&conteud $\mathrm{o}=. /$ gestao/artigos/wwi.html $>$ Acesso em: maio 2008 . 
IPCC/ONU, Novos Cenários Climáticos. Relatório (2007) Disponível em: $<$ http://www.ecolatina.com.br/pdf/IPCC-COMPLETO.pdf >Acesso em: maio 2008.

ISTO É DINHEIRO. O mundo em guerra pelo pão. n. 0551. Disponível em: $<$ http://clipping.planejamento.gov.br/Noticias.asp?NOTCod=425576> Acesso em: maio 2008

MACEDO, I.C., SEABRA, J.E.A., SILVA, J.E.A.R., Green house gases emissions in the production and use of ethanol from sugarcane in Brazil: The 2005/2006 averages and a prediction for 2020, Biomass and Bioenergy, v. 32, Issue 7, July 2008, p.582-595.

MERCADOS, Cotação da tonelada de $\mathrm{CO}_{2}$ sobe para 16,85 euros. Disponível em:< http://invertia.terra.com.br/carbono/interna/0,OI2922278-EI8939,00.html> Acesso em: jun. 2008.

OECD/IEA, The energy situation in Brazil: an overview. May 2006. Disponível em: http://www.iea.org/textbase/papers/2006/brazil.pdf. Acesso em: maio 2008.

ROSEGRANT, M.W. Biofuels and Grain Prices: Impacts and Policy Responses, International Food Policy Research Institute, Testimony for the U.S. Senate Committee on Homeland Security and Governmental Affairs, May 7 (2008) Disponível em: $\quad<$ http://www.ifpri.org/pubs/testimony/vonbraun20080612.asp $>$. Acessado em set/2008.

SEARCHINGER, T. et al, Use of U.S. Croplands for Biofuels Increases Greenhouse Gases Through Emissions from Land-Use Change, Science 319, 1238 (2008).

SILVA, C.R.L.; CARVALHO, M. A. de, Biocombustíveis e Insegurança Alimentar, Análises e informações do agronegócio, v.2, n.7, julho 2007.

STERN, N. Tempo de termos a mesma consciência Stern nas Alterações Climáticas. 31/10/2006. In: Economia das mudanças climáticas. Disponível em: $<$ http://bioterra.blogspot.com/2007/12/tempo-de-termos-mesma-conscincia-stern.html $>$. Acesso em: jun. 2008.

VERLI, L. Se o etanol substituir a gasolina, faltará comida no mundo? Planeta Sustentável. em: $<$ http://planetasustentavel.abril.com.br/noticia/desenvolvimento/conteudo_231773.shtm 1> Acessado em: maio 2008. 